\title{
Should Avastin be used to treat age-related macular degeneration in the NHS? - No
}

Eye (2009) 23, 1250-1253; doi:10.1038/eye.2009.84; published online 1 May 2009

I would like to make it clear from the very beginning that I am not against the use of Avastin in the National Health Service (NHS), but just not in neovascular age-related macular degeneration (AMD). I am also not saying that we should never use Avastin for neovascular AMD in the NHS, but just not now, in 2009. So what is missing and why not? Let me take you through my logic from different perspectives.

\section{From the scientist's point of view}

Let me explain the differences between Avastin and Lucentis. Avastin is the full-size molecule of the antibody of vascular endothelial growth factor (VEGF), whereas Lucentis is only the fragment that has the receptor of binding VEGF. Lucentis is smaller in size, so in theory, it gets through the retina more rapidly ${ }^{1}$ and hence might work faster. Avastin can get through the normal rabbit retina ${ }^{2}$ and as it is effective in AMD, it should get through at least the diseased retina.

The receptor site in Lucentis has been modified to increase the affinity to $\mathrm{VEGF}^{3}$ and it is about 100 times more, so in theory, Lucentis binds to VEGF more tightly and hence, potentially, is more effective even at a lower dose.

There is a mechanism to eliminate the full-size antibody through the Fc component of the antibody from the eye back to the circulation. Avastin has the Fc component intact whereas Lucentis does not. Therefore, Avastin is actively moved from the eye to the circulation whereas Lucentis is allowed to degrade in the eye. More importantly, Avastin can accumulate in platelets and increases its systemic half-life.
In a rabbit at least, one can measure Avastin in the systemic circulation for 29 days ${ }^{4}$ whereas Lucentis is not detectable. ${ }^{5}$ In primates, Avastin can be found in the systemic circulation after intravitreal injection for weeks but Lucentis can be found at most for $2 \mathrm{~h}$ after the injection. ${ }^{1}$

Both molecules are humanised mouse antibody, therefore immune response is possible; the risk is higher with Avastin as it is a larger molecule with the Fc component and is in the circulation for longer. Clinically that does not seem to be a big problem, but nonetheless, it is a risk more for Avastin than Lucentis, especially after multiple injections.

Therefore, in summary, Lucentis stays in the eye, penetrates the retina faster, binds VEGF more tightly, has a lesser risk of immune response, and a lesser risk of systemic side effects.

\section{From the clinical trialist's prospective}

Prospective double-masked randomised controlled trials are the current gold standard of evidence-based clinical practice. The case for Lucentis cannot be disputed. It is better than no treatment with occult choroidal neovascularisation (CNV) in the MARINA trial, ${ }^{6}$ and it is better than photodynamic therapy with predominantly classic $\mathrm{CNV}$ in the ANCHOR trial. ${ }^{7}$ Most recently, it has been shown that it improves patients' quality of life. ${ }^{8}$

At the time of writing, no prospective randomised controlled trial for Avastin in neovascular AMD has been published. ${ }^{9}$ Many people think it works. In fact, I think it works as well. But there is no evidence that it is better than Lucentis and I cannot even think of any theoretical reason that it would be more effective than Lucentis. I used to think intravitreal triamcinolone is better than laser for diabetic macular oedema but in a recent 
published prospective randomised controlled trial, it turns out that that is not the case at year 2; more importantly, there were more complications from intravitreal triamcinolone. ${ }^{10}$

Therefore, in summary, Lucentis has a gold standard proof of effectiveness both in visual acuity and quality of life in multiple studies, whereas Avastin provides anecdotal evidence in retrospective case series.

\section{From the health economist's point of view}

The most common argument that I have heard of using Avastin is that it is just as good, and it is so much cheaper that it is crazy not to use it. The question then is whether it is really cheaper?

In using either drug, we would still need to see the patients on monthly basis and treat them as needed, so there is no difference in the infrastructure cost. Avastin is only significantly cheaper if it is divided up in multiple doses from a single vial. Moreover, the drug has to be stored at $4{ }^{\circ} \mathrm{C}$ during transport as well as storage, and has a short shell life. People who have worked in the NHS would know that many things can go wrong. Drugs can be easily needed to be thrown away because of the short shell life, and failure to store at $4{ }^{\circ} \mathrm{C}$ might leading to reduced efficacy and potential contamination. What if there is a $1 \%$ increase risk in endophthalmitis rate? Approximately 25000 patients will be treated in a year, which means we would have 250 more endophthalmitis a year. We will not know that until it is studied properly.

In November, 2008, Roche (the distributor of Avastin in Canada) was made aware of 25 spontaneously reported Canadian cases of eye inflammation, endophthalmitis, blurred vision, and floaters, some of which have been described as Toxic Anterior Segment Syndrome (TASS), in patients who were administered aliquots of AVASTIN Lot B3002B028 intravitreally. ${ }^{11}$ Roche and Genentech have repeated their warnings; the manufacturing standard for intravenous use (ie, for Avastin) is different from that of intravitreous use (ie, for Lucentis). They also re-enforced that Avastin should not be used as an intravitreal injection.

A similar argument can be used for the systemic side effects as well. Although in individual studies, Lucentis did not show a statistically significant increase in stroke rate, adding all the studies together, suggested a slight increase in stroke rate. More so, in the SUSTAIN study, in which about $10 \%$ of patients who had a stroke earlier developed another stroke in the first 12 months. One explanation is that Lucentis does not leak out of the eye in normal circumstances, but if there is a breakdown of the blood retinal barrier as in AMD, some of the drug might manage to get into the systemic circulation. Even that small amount can potentially lead to a small increase in stroke rate. Therefore, in Avastin-injected patients, Avastin circulates in the body for more than 28 days. There were several case reports that when an intravitreal injection of Avastin was given for proliferative diabetic retinopathy, the new vessels in the fellow eye disappeared as well; therefore, it is clearly biologically active even at a very small dose. ${ }^{12}$ One cannot help but think that there might be a theoretical increase of a systemic side effect. Again, if there is a $1 \%$ increase in stroke rate, there will be 250 more stroke patients. Is it really cheaper for the NHS?

\section{From the retinal specialist's point of view}

On the basis of our current understanding, there is no evidence that Avastin is superior to Lucentis, and in theory, Avastin might have more local and systemic side effects. Therefore, how can we justify using an off-label treatment when a licensed alternative is available?

In a recent GMC article with specific reference to Avastin, 'GMC's guidance states that doctors must be satisfied that prescribing off-label would better serve the patient's needs than use of an appropriately licensed alternative. It is the prescribing doctor's decision to prescribe off-label. They should be satisfied that there is a sufficient evidence base or experience of using the medicine to show its safety and efficacy to justify prescribing off-label. The costs of prescribing different drugs is often a concern for doctors, and rightly so if they are to make efficient use of available resources in caring for all their patients. But cost alone cannot be the determining factor in a doctor's decision about which drugs to prescribe. ${ }^{13}$ In other words, with current evidence on Avastin for AMD when there is a proven licensed alternative, Lucentis, prescribing Avastin for AMD does not meet GMC guidance on good medical practice.

Moreover, why do ophthalmologists have to be the people balancing the financial books of the NHS? The government has been wasting money left, right and centre in the NHS. Have we not suffered enough? We were told by the government that the independent treatment centres have significantly reduced the cataract waiting list; as if we have not treated any of these cataracts in the NHS.

We should give the best care to our patients and, at the moment, Lucentis is the best care for neovascular AMD.

\section{From the patient's point of view}

Can anyone explain to the patients that we can either treat them with a licensed proven drug, Lucentis, or give them Avastin that is not licensed, that it might work but no better, and there is a theoretical increase in the rate of 
complications. I wonder how many patients will choose Avastin. I am quite sure what I will choose; so why deny our patients what we would choose for ourselves or for our families. Is it really ethical to give anything else rather than Lucentis in 2009?

\section{What is happening next?}

First of all, we need to confirm the efficacy of Avastin in neovascular AMD. At least two large prospective trials in the United States and UK are ongoing comparing Avastin versus Lucentis. However, both studies are limited to the non-inferiority study design and are not empowered to study systemic side effects. Therefore, we will only know that Avastin is similar to Lucentis. And we will not be able to pick up the $1 \%$ increase of endophthalmitis or stroke to a statistically significant level.

On account of regulatory reasons, I am unclear, even if the studies show that Avastin and Lucentis are similar in efficacy, whether we can justify using Avastin in the NHS. Hence, regulatory and legal advice should be sought. The situation in the United States is different, as they have the co-payment system, so patients might chose to use the cheaper drug to reduce their cost after understanding the theoretical risks. In the UK, even after these studies are published, Avastin remains off-label. And if both are offered in the NHS, I doubt any sensible patient will pick Avastin, if only Avastin is offered in the NHS. I am not sure that this is legal unless NICE re-classifies Lucentis as not being cost-effective in their next review.

\section{What about using Avastin for other indications in the NHS?}

Personally, I think we should not waste any more time and effort in trying to use Avastin for neovascular AMD in the NHS.

We should work together to lobby the primary care trusts (PCT) to pay for Avastin in the NHS for proliferative diabetic retinopathy, ${ }^{12,14}$ diabetic macular oedema, ${ }^{15,16}$ retinal vein occlusion, ${ }^{17}$ and in particular, rubeosis. ${ }^{18,19}$ There is some evidence to suggest that Avastin is more effective than the current treatment in these conditions, as it will meet the basic rule of using an off-label drug, that is, there is no licensed alternative. Lucentis might be better but it is not licensed for these conditions either. It would be nice if PCTs will pay for Lucentis, in the absence of that, paying for Avastin might be a reasonable first step.

\section{Conclusion}

My case for NO is simple. Lucentis is proven; Avastin is not and has theoretical risks. GMC guidance does not accept using Avastin for AMD in the NHS as good medical practice. And it might not be cheaper after all.

\section{Acknowledgements}

The author has received honorarium, travel grants and/or speaker fees from Novartis, Bayer, Allergan and Merck in the past 12 months.

\section{References}

1 Gaudreault J, Fei D, Rusit J, Suboc P, Shiu V. Preclinical pharmacokinetics of Ranibizumab (rhuFabV2) after a single intravitreal administration. Invest Ophthalmol Vis Sci 2005; 46: 726-733.

2 Shahar J, Avery RL, Heilweil G, Barak A, Zemel E, Lewis GP et al. Electrophysiologic and retinal penetration studies following intravitreal injection of bevacizumab (Avastin). Retina 2006; 26: 262-269.

3 Chen Y, Wiesmann C, Fuh G, Li B, Christinger HW, McKay $\mathrm{P}$ et al. Selection and analysis of an optimized anti-VEGF antibody: crystal structure of an affinitymatured Fab in complex with antigen. J Mol Biol 1999; 293: 865-881.

4 Bakri SJ, Snyder MR, Reid JM, Pulido JS, Singh RJ. Pharmacokinetics of intravitreal bevacizumab (Avastin). Ophthalmology 2007; 114: 855-859.

5 Bakri SJ, Snyder MR, Reid JM, Pulido JS, Ezzat MK, Singh RJ. Pharmacokinetics of intravitreal ranibizumab (Lucentis). Ophthalmology 2007; 114: 2179-2182.

6 Rosenfeld PJ, Brown DM, Heier JS, Boyer DS, Kaiser PK, Chung CY et al., MARINA Study Group. Ranibizumab for neovascular age-related macular degeneration. $N$ Engl J Med 2006; 355: 1419-1431.

7 Brown DM, Michels M, Kaiser PK, Heier JS, Sy JP, Ianchulev T, ANCHOR Study Group. Ranibizumab versus verteporfin photodynamic therapy for neovascular age-related macular degeneration: Two-year results of the ANCHOR study. Ophthalmology 2009; 116: 57-65. e5.

8 Bressler NM, Chang TS, Fine JT, Dolan CM, Ward J, ANCHOR study group. Improved vision-related function after ranibizumab vs photodynamic therapy: a randomized clinical trial. Arch Ophthalmol 2009; 127: 13-21.

9 Ip MS, Scott IU, Brown GC, Brown MM, Ho AC, Huang SS et al. American Academy of Ophthalmology. Anti-vascular endothelial growth factor pharmacotherapy for age-related macular degeneration: a report by the American Academy of Ophthalmology. Ophthalmology 2008; 115: 1837-1846.

10 Diabetic Retinopathy Clinical Research Network. A randomized trial comparing intravitreal triamcinolone acetonide and focal/grid photocoagulation for diabetic macular edema. Ophthalmology 2008; 115: 1447-1449, 1449.e1-10]

11 http://www.hc-sc.gc.ca/dhp-mps/medeff/advisories-avis/ prof/_2008/avastin_4_hpc-cps-eng.php. Accessed on 28 February 2009.

12 Avery RL, Pearlman J, Pieramici DJ, Rabena MD, Castellarin AA, Nasir MA et al. Intravitreal bevacizumab (Avastin) in the treatment of proliferative diabetic retinopathy. Ophthalmology. 2006; 113: 1695. e1-15.

13 Prescribing off-label. GMC today 2008. 
14 Yeoh J, Williams C, Allen P, Buttery R, Chiu D, Clark B et al. Avastin as an adjunct to vitrectomy in the management of severe proliferative diabetic retinopathy: a prospective case series. Clin Experiment Ophthalmol 2008; 36: 449-454.

15 Arevalo JF, Sanchez JG, Fromow-Guerra J, Wu L, Berrocal $\mathrm{MH}$, Farah ME et al. Comparison of two doses of primary intravitreal bevacizumab (Avastin) for diffuse diabetic macular edema: results from the Pan-American Collaborative Retina Study Group (PACORES) at 12-month follow-up. Graefes Arch Clin Exp Ophthalmol 2009; 3 February 2009 [E-pub ahead of print].

16 Velez-Montoya R, Fromow-Guerra J, Burgos O, Landers III MB, Morales-Catón V, Quiroz-Mercado H. The effect of unilateral intravitreal bevacizumab (avastin), in the treatment of diffuse bilateral diabetic macular edema: a pilot study. Retina 2009; 29: 20-26.

17 Prager F, Michels S, Kriechbaum K, Georgopoulos M, Funk M, Geitzenauer W et al. Intravitreal bevacizumab $(\operatorname{Avastin}(\mathrm{R}))$ for macular edema secondary to retinal vein occlusion - twelve-month results of a prospective clinical trial. Br J Ophthalmol 2008; 15 December 2008

[E-pub ahead of print].
18 Beutel J, Peters S, Lüke M, Aisenbrey S, Szurman P, Spitzer MS et al. Bevacizumab as adjuvant for neovascular glaucoma. Acta Ophthalmol 2008; 20 September 2008; [E-pub ahead of print].

19 Wakabayashi T, Oshima Y, Sakaguchi H, Ikuno Y, Miki A, Gomi $\mathrm{F}$ et al. Intravitreal bevacizumab to treat iris neovascularization and neovascular glaucoma secondary to ischemic retinal diseases in 41 consecutive cases. Ophthalmology 2008; 115: 1571-1580, 1580.e1-3.

NV Chong

Oxford Eye Hospital, University of Oxford, England, Oxford, UK

Correspondence: NV Chong, Oxford Eye Hospital,

University of Oxford, Oxford OX3 9DU, UK.

Tel: +44 1865234 736;

Fax: +44 1865234 515;

E-mail: victor.chong@eye.ox.ac.uk 